\title{
Combined collection and analysis of inorganic and organic gunshot residues $* * * *$
}

\author{
Virginie Redouté Minzière ${ }^{1}$, Denis Werner ${ }^{1}$, Daniela Schneider ${ }^{2}$, \\ Manuela Manganelli², Balthasar Jung ${ }^{2}$, Céline Weyermann ${ }^{1}$, Anne-Laure Gassner ${ }^{1}$ \\ ${ }^{1}$ Ecole des Sciences Criminelles, University of Lausanne, Bâtiment Batochime, 1015, Lausanne, Switzerland \\ ${ }^{2}$ Forensic Science Laboratory, Kantonspolizei Aargau, Tellistrasse 85, 5000, Aarau, Switzerland \\ Corresponding author: Virginie Redouté Minzière, E-mail:virginie.redouteminziere@unil.ch
}

* Presented at the 25th Annual Meeting of ENFSI Firearms/GSR Working Group, October 3-5, 2018, in Copenhagen, Denmark
** Support for the research provided by the Swiss National Science Foundation (Grant 10521A_165608 and 105211_188898)

\begin{abstract}
Gunshot residues (GSR) analysis and their interpretation provide crucial information on a criminal investigation involving the use of firearms. To date, several approaches have been proposed for the implementation of a combined sampling and analysis of inorganic (IGSR) and organic GSR (OGSR). However, it is not clear at this stage if concurrent analyses of both types of residue might be detrimental to the analysis of IGSR currently applied in forensic laboratories. Thus, this work aims to compare and evaluate three different protocols for the combined collection and analysis of IGSR and OGSR. These methods respectively involve the use of a modified stub (with two halves, one for the detection of IGSR and the other for the analysis of OGSR); the sequential recovery of GSR with two stubs mounted with different adhesives (double-sided carbon tape and Tesa ${ }^{\circledR}$ TACK) and the sequential analysis of IGSR and OGSR from a single carbon stub following carbon deposition. The detection of IGSR was carried out using SEM-EDX, while OGSR analysis was performed using ultra-high-performance liquid chromatography tandem mass spectrometry (UHPLC-MS/MS). Obtained results for experiments performed using Geco Sinoxid ${ }^{\circledR}$ ammunition indicated that sequential analysis was the most suitable protocol for the combined collection and analysis of both IGSR and OGSR. A higher number of inorganic (characteristic and consistent) particles and higher concentrations of ethylcentralite, $\mathrm{N}$-nitrosodiphenylamine, diphenylamine and nitroglycerin were recovered with this method.
\end{abstract}

Keywords: Firearm discharge residue ; Inorganic gunshot residues ; Organic gunshot residues ; Scanning electron microscopy - energy dispersive x-ray spectroscopy (SEM-EDX) ; Liquid chromatography ; Mass spectrometry.

\section{Introduction}

Following the discharge of a firearm, particles known as gunshot residues (GSR) can be deposited on the hands, clothes, hair, and face of the shooter as well as on the target, the bystander(s) and the environment. GSR include two categories of compounds: organic GSR (OGSR) originating from the propellant powder and lubricants, and inorganic GSR (IGSR) produced by the primer as well as metals present in the ammunition (bullet and cartridge) and the firearm $(1,2)$. To date, analysis of GSR focuses mainly on the IGSR detection using scanning electron microscopy coupled with energy dispersive X-ray spectroscopy (SEM-EDX). This technique is non-destructive and provides information on the morphology and the elemental composition of a particle. The methodology for this category of compounds is well established. A standard protocol is proposed by the American Society for Testing and Materials (ASTM E1588-17 (3)), in addition to guidelines and recommendations by GSR working groups such as the National Institute of Standards and Technology (NIST) and the European Network of Forensic Science Institute (ENFSI) $(4,5)$. According to the ASTM standard, a particle can be classified as characteristic, consistent or commonly associated with GSR. Characteristic particles have the highest probative value since particles with these compositions (antimony, barium and lead $(\mathrm{SbBaPb})$ or lead, barium, calcium, silicon and tin $(\mathrm{PbBaCaSiSn}))$ are rarely found from any other source. Particles classified as consistent or commonly associated with GSR have a lower probative value since the elemental composition of these two groups is also found in a number of non-firearm sources. Thus, during a criminal investigation, the number of characteristic particles detected on a person's hands, clothes, hair or face is a key result used to infer about the involvement of a person in firearm discharge events (6-8).

Lead-free and heavy metal-free ammunitions have been introduced due to concerns about the release of toxic elements (i.e. lead, barium and antimony) in the environment by heavy metal ammunitions. Nowadays, hunters and police officers use these heavy metal-free ammunitions more frequently because of the toxicity of lead in animals, humans and environment (9-11). For the majority of these ammunitions, no characteristic particles are 
produced, since the primers are composed of copper, zinc, tin, titanium, barium and strontium (12, 13). Only consistent particles, with a lower probative value, are released. In such cases, a combined analysis of IGSR and OGSR might improve the probative value of GSR. A combined analysis will also provide additional information for the characterization of materials found on a person (hands, clothes, face or hair). It is important to specify that some lead-free ammunition used by police forces produce characteristic particles due to the addition of a specific tagging element in the powder. Action 4 (from RUAG Ammotec), Quick Defense Polizei-Einsatz-Patrone (from Munitionsfabrik Elisenhütte Nassau, MEN) and FIOCCHI-RIS (from Fiocchi Munizioni) each contain one of the following tagging elements; gadolinium, gallium and samarium, respectively $(14,15)$. Therefore, the particles from such ammunitions can easily be identified by SEM-EDX. Even though a large number of lead-free or heavy metal-free ammunitions are available on the market, heavy metal ammunitions are still widely used due to their lower price.

Contrary to IGSR analysis, no standard practice has yet been proposed for a harmonized methodology to detect OGSR. However, it is important to underline that a classification of OGSR was recently developed and introduced by Goudsmits et al. (16). OGSR includes molecules derived from explosives, sensitizers, stabilizers, flash inhibitors and plasticizers $(17,18)$. The main OGSR compounds present in ammunition powders are nitrocellulose (NC), nitroglycerin (NG), nitroguanidine (NQ), diphenylamine (DPA), methylcentralite (MC), ethylcentralite (EC), 2,4-dinitrotoluene (2,4-DNT), 2-nitrodiphenylamine (2-nDPA), 4-nitrodiphenylamine (4nDPA), akardite II (AK-II) and N-nitrosodiphenylamine (N-nDPA) (19-21). Several research groups have developed methods for the analysis of OGSR, liquid chromatography tandem mass spectrometry (LC-MS/MS) reported to be an effective approach due to its sensitivity and selectivity (17, 20-24).

Several studies have also proposed a combined collection and/or analysis of IGSR and OGSR (19, 25-33) (Table 1). Each of these proposed protocols has advantages and drawbacks, as none of them allow the complete recovery of both IGSR and OGSR. Sampling can either be performed with one or two collection devices, such as adhesive stubs or humidified swabs. One example of a combined protocol is the use of a modified carbon stub for the collection of both types of residue $(19,25)$. Half of the stub was covered with PTFE for the collection of OGSR, while the other half remained coated with carbon adhesive for IGSR. Such protocols have been named fifty-fifty sampling and can easily be implemented in routine collection procedure. However, the recovered quantities of both types of residue will be half of what would be collected if a whole stub was used for each GSR type; possibly even less if GSR distribution is inhomogeneous on the stub. Some research groups have suggested the use of two collection devices for the sequential sampling of IGSR and OGSR (26, 34). While these can easily be implemented in routine procedures, especially when both types of residue are collected using stub-type devices, extra time and material are needed for the collection. Moreover, it has to be decided what type of residue is collected first and where, as significant loss of the other GSR type might be sustained during this first collection step. Finally, some research suggests that only one specimen might be collected and analyzed sequentially using two instruments (27-31) or even simultaneously using one versatile technique $(32,33)$. Sequential analysis can either be performed when the target molecules (IGSR and OGSR) are collected from a single specimen (generally a swab) separated during a sequential extraction $(26,27)$ or when a specimen, generally a stub, is first analyzed for IGSR (potentially sustaining OGSR loss) before being analyzed for OGSR (27-30). While simultaneous analysis is theoretically very interesting, no method currently allows sufficient sensitivity for both types of residue. LC-MS and capillary electrophoresis (CE) were both investigated for this purpose but yielded only a limited number of compounds and elements $(32,33)$. Moreover, the obtained sensitivities were not as good as when the whole protocol was optimized for a specific residue type.

The aim of this research was to evaluate different approaches for the combined collection and analysis of IGSR and OGSR. Methods were selected among those described in Table 1. The choice was based on the analytical technique and collection device used. SEM-EDX and UHPLC-MS/MS were used for the analysis of IGSR and OGSR, respectively. In order to follow current practices, stubs were used as collection devices. Their efficiency for the collection of both types of residue has been demonstrated previously; moreover, stubs can be directly analyzed using SEM-EDX and are easily extracted for LC-MS analysis (3, 17, 34). Sequential sampling, fiftyfifty sampling, and sequential analysis approaches were each tested. The sequential sampling protocol utilised two different adhesives to collect GSR as suggested in a research carried out by the Federal Criminal Police Office of Germany (Bundeskriminalamt) (34). The fifty-fifty protocol was based on work by Benito et al. whereby residues were collected using a modified carbon stub (19). Finally, the third protocol evaluated the efficiency of sequential analysis of one carbon stub $(19,28)$. Each of the three protocols were compared to determine the best approach for forensic practice. Data were obtained for ten replicates collected immediately after discharge of a firearm with Geco Sinoxid ${ }^{\circledR}$ ammunition. 
Table 1. Summary of studies proposing a combined analysis of IGSR and OGSR.

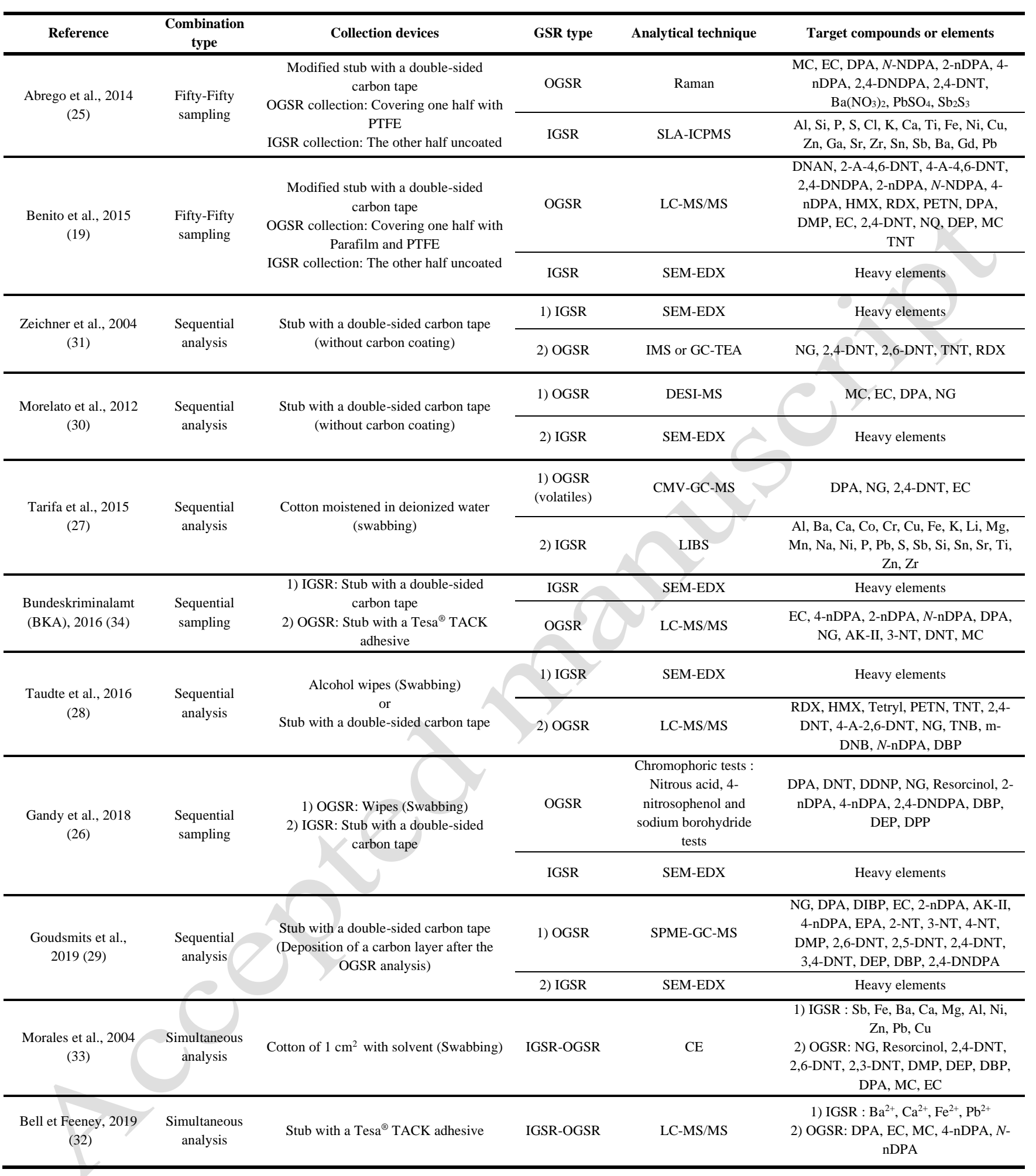

* SLA-ICPMS, Scanning Laser Ablation and Inductively Coupled Plasma-Mass Spectrometry; LIBS, Laser-Induced Breakdown Spectroscopy; CMV, Capillary Microextraction of Volatiles; GC, Gas Chromatography; MS, Mass Spectrometry; SPME, Solid-Phase MicroExtraction; DESI, Desorption ElectroSpray Ionization; TEA, Thermal Energy Analyser; IMS, Ion Mobility Spectrometry; DNDPA, Dinitrodiphenylamine; DNAN, 2,4-Dinitroanisole; X-A-X,X-DNT, X-Amino-X,X-dinitrotoluene; HMX, octogen; RDX, cyclonite; PETN, Pentaerythritol tetranitrate; DMP, Dimethyl phthalate; NQ, nitroguanidine; DEP Diethyl phthalate; TNT, Trinitrotoluene; NT, Nitrotoluene; DDNP, Diazodinitrophenol; DBP, Dibutyl phthalate; DPP, Dipentyl Phthalate; TNB, Trinitrobenzene; DNB, Dinitrobenzene. 


\section{Material and methods}

\subsection{Shooting sessions}

Shooting sessions were conducted in an indoor shooting range. The ventilation was turned off during the experiments. The firearm used for all tests was a semi-automatic $9 \mathrm{~mm}$ Parabellum Sig Sauer P226. Geco Sinoxid ${ }^{\circledR}$ ammunition containing heavy metal was utilized (124 gr, FMJ, batch 51 B L024). Before the experiments, the firearm was completely dismantled, cleaned and lubricated with WD- $40^{\circledR}$. Ten consecutive discharges were then performed with the Geco Sinoxid ${ }^{\circledR}$ ammunition to minimize potential memory effects before the experiments.

Before the experiments and after each collection of GSR, the outer parts of the firearm and the magazine were cleaned with ethanol to minimize the risks of GSR accumulation and contamination (by another person than the shooter). To ensure a certain level of repeatability in the execution of the firing, the same person fired all replicates holding the firearms with both hands. The shooter washed his hands with soap before each discharge and all specimens were collected from the dominant hand following three consecutive discharges. The dominant hand was defined as the one that pressed the trigger. The collection of GSR was performed directly after the firing (within 5 minutes). Large concentrations of GSR were thus expected under these conditions.

\subsection{Combined protocols for the analysis of OGSR and IGSR}

Three protocols were evaluated and compared for the combined sampling and analysis of IGSR and OGSR. Forty specimens were collected in total (10 each for the fifty-fifty and sequential analysis samplings, and 20 for the sequential sampling method as 2 stubs were required per replicate). Carbon stubs from Plano (Wetzlar, Germany) were used for the recovery of OGSR and IGSR. These stubs consist of an aluminum stub mounted with a double-sided adhesive and inserted in a screw cap vial. Depending on the protocol, two adhesive types were utilized (see the sequential sampling protocol). After the sampling, the specimens were stored at $4^{\circ} \mathrm{C}$ until analysis using SEM-EDX or UHPLC-MS/MS.

\subsubsection{Sequential sampling}

The first protocol used two separate stubs for the collection of IGSR and OGSR (Figure 1). The first stub mounted with a double-sided carbon adhesive $12 \mathrm{~mm}$ in diameter from Plano (Wetzlar, Germany) was used for the collection of IGSR. The stub was dabbed 15 times on the area of the dominant hand between the thumb and the forefinger, as previous research reported that large amounts of GSR are generally deposited here due to the proximity to gases escaping the firearm openings $(1,35)$. The amount of dabbing was kept low and limited to a small, relevant section of the hand in order to still be able to collect OGSR using a second stub. This latter was mounted with $1 \mathrm{~cm} 2$ of a Tesa ${ }^{\circledR}$ TACK adhesive (bought from a local supermarket), an adhesive utilized in studies for the collection of OGSR $(32,34)$. Between 50 and 100 dabbings were used (until the adhesive lost its stickiness) in order to recover as much OGSR left on the hand as possible. According to Zeichner et al. (36), 50 to 100 dabbings are necessary to achieve the maximum collection of GSR. The dabbings were performed on the area between the thumb and forefinger, as well as on the remaining parts of the palm and back of the dominant hand of the shooter (excluding fingers).

Figure 1. Schematic representation of the Sequential sampling protocol. After collection, Stub 1 was analysed for IGSR using SEMEDX, while a liquid extraction was performed on Stub 2 for recovery of OGSR using UHPLC-MS/MS.

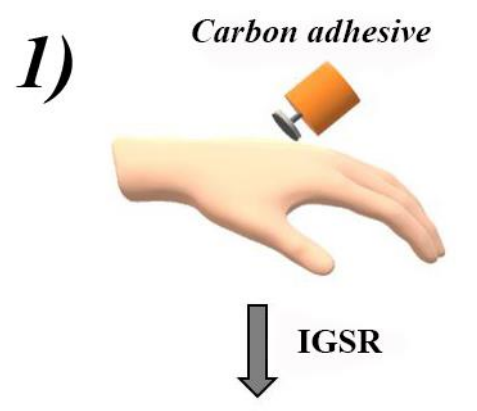

SEM-EDX

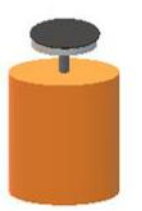

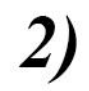

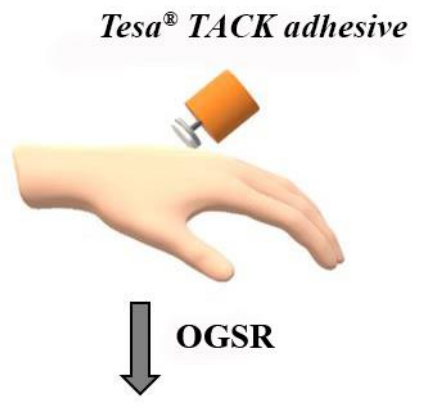

UHPLC-MS/MS
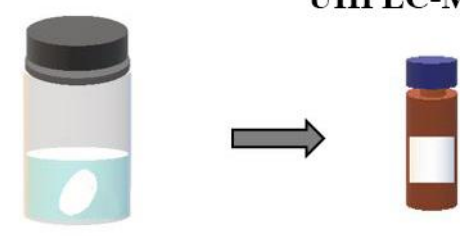


\subsubsection{Fifty-Fifty sampling}

The second protocol aimed at using only one carbon stub for the collection of both IGSR and OGSR. The stub was divided into two halves, the first one for IGSR analysis using the SEM-EDX and the second one for OGSR analysis using UHPLCMS/MS (Figure 2). To prepare this modified stub, two double-sided carbon adhesives were fixed on the stub and a cleaned scalpel was used to cut the upper adhesive layer into two halves. It was important to avoid cutting the aluminum substrate under the adhesives as this produced aluminum particles causing interference during SEM-EDX analysis. The stub was dabbed 50 to 100 times on the dominant hand of the shooter (thumb and forefinger area, back and palm excluding the fingers).

Figure 2. Schematic representation of the Fifty-Fifty sampling protocol. After collection, one half of the adhesive was analysed for IGSR using SEM-EDX, while a liquid extraction was performed on the other half for recovery of OGSR and subsequent analysis using UHPLC-MS/MS.
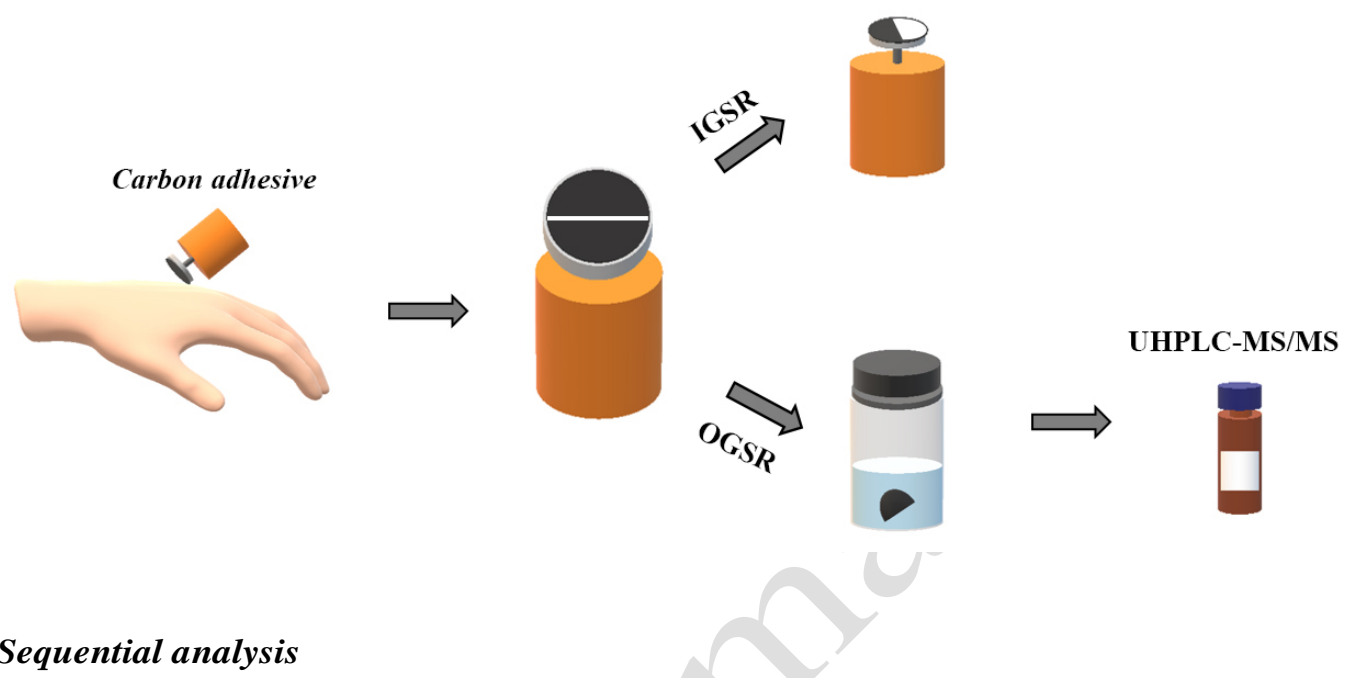

SEM-EDX

\subsubsection{Sequential analysis}

The third protocol used one stub mounted with a carbon adhesive for the combined collection of IGSR and OGSR (see Figure 3). The stub was dabbed 50 to 100 times on the dominant hand of the shooter as described for the fifty-fifty sampling. Then, a carbon layer was deposited on the adhesive before the SEM-EDX analysis (this is generally suggested to avoid potential charging effects caused by the presence of fibers or dust on the adhesive (37)). It was hypothesized that this carbon layer might also slow the evaporation of the OGSR in the vacuum used for SEM-EDX analysis of the IGSR, thus minimizing potential loss. Following IGSR analysis using SEM-EDX, the OGSR were extracted from the adhesive and analyzed using UHPLC-MS/MS.

Figure 3. Schematic representation of the Sequential analysis protocol. After collection, a carbon layer was deposited on the adhesive and IGSR were analysed using SEM-EDX. Then, OGSR were extracted and analysed using UHPLC-MS/MS.

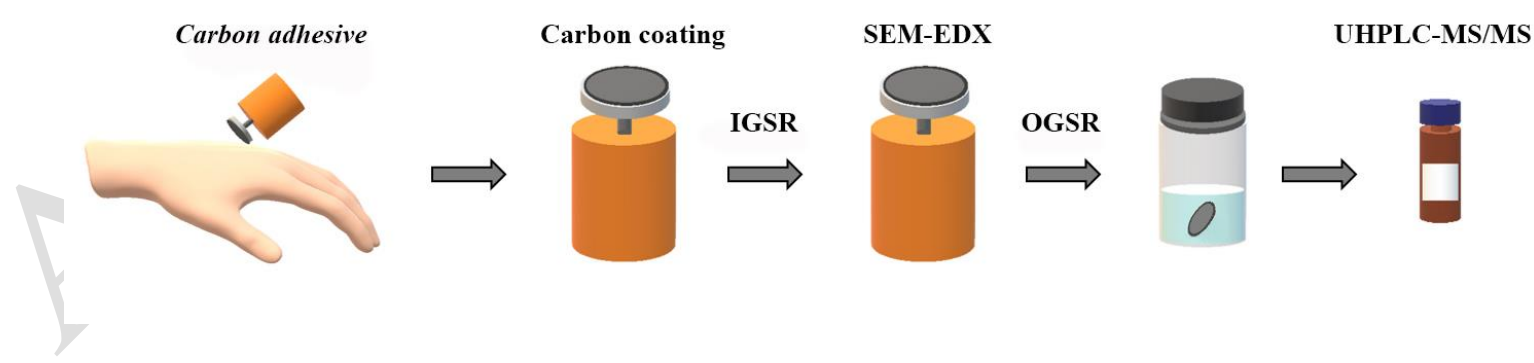

\subsection{Specimen extraction for OGSR recovery}

The adhesive was carefully removed from the stub with cleaned tweezers and deposited in a $20 \mathrm{~mL}$ scintillation vial (SigmaAldrich, Buchs, Switzerland) containing $1 \mathrm{~mL}$ of methanol (grade ULC-MS from Biosolve, Dieuze, France). The OGSR were then solubilized by sonication for 15 minutes at room temperature. Finally, the solution was filtered through $0.2 \mu \mathrm{m}$ Chromafil PTFE syringe filter (Macherey-Nagel, Düren, Germany). Extracts were stored in the freezer at $-24{ }^{\circ} \mathrm{C}$ until UHPLC-MS/MS analysis. 
Additionally, to detect contamination that could occur during sample preparation, a stub was stored for 72 hours in the laminar flow hood used for the preparation and extraction of OGSR. Blank solutions were also prepared to identify contamination that may occur during the extraction of OGSR. To this end, a fraction of the methanol used as solvent was collected after the extraction of specimens.

\subsection{Instrumentation}

\subsubsection{Carbon Coater}

Carbon deposition was performed with a CCU-010 HV Compact Coating Unit from Safematic GmbH (Bad Ragaz, Switzerland). A carbon layer was deposited on the specimens following the evaporation of a carbon fiber thread under a vacuum of $5 \times 10-5$ mbar. The instrument was also equipped with a quartz sensor to evaluate the thickness of the carbon layer. A carbon thickness of $5.5 \mathrm{~nm}$ and a current of $12.5 \mathrm{~mA}$ was determined to be adequate for subsequent OGSR extraction. Tests were performed with spiked stubs to determine the current and thickness values generating minimal loss of GSR.

\subsubsection{UHPLC-MS/MS analysis}

Chromatographic separation was performed using an ExionLCTM ultra-high-performance liquid chromatography from AB Sciex. The instrument was equipped with an autosampler, a binary pump and a thermostat for the column compartments. Analysis was performed in positive and negative mode. Acetonitrile, methanol and formic acid were ULC-MS grade and were purchased from Biosolve (Dieuze, France) while ammonium acetate and water were LC-MS grade and were obtained from Sigma-Aldrich (Buchs, Switzerland). A Kinetex Core-Shell C18 LC column (2.6 $\mu \mathrm{m} \times 2.1 \mathrm{~mm} \times 100 \mathrm{~mm})$ from Phenomenex was maintained at $40{ }^{\circ} \mathrm{C}$ for the UHPLC-MS/MS analyses. The specifications and the gradient flow for each mode are presented in Table 2.

Table 2. UHPLC parameters.

\begin{tabular}{|c|c|c|c|c|c|c|}
\hline Ionization & \multicolumn{3}{|c|}{ Positive mode } & \multicolumn{3}{|c|}{ Negative mode } \\
\hline Flow rate & \multicolumn{3}{|c|}{$0.25 \mathrm{~mL} / \mathrm{min}$} & \multicolumn{3}{|c|}{$0.40 \mathrm{~mL} / \mathrm{min}$} \\
\hline $\begin{array}{l}\text { Injection } \\
\text { volume }\end{array}$ & \multicolumn{3}{|c|}{$5 \mu \mathrm{L}$} & \multicolumn{3}{|c|}{$2 \mu \mathrm{L}$} \\
\hline \multirow[b]{2}{*}{$\begin{array}{l}\text { Gradient } \\
\text { method }\end{array}$} & \multirow[b]{2}{*}{$\begin{array}{l}\text { Time } \\
{[\mathrm{min}]}\end{array}$} & \multicolumn{2}{|c|}{ Mobile phases } & \multirow[b]{2}{*}{$\begin{array}{l}\text { Time } \\
{[\text { min] }}\end{array}$} & \multicolumn{2}{|c|}{ Mobile phases } \\
\hline & & $\begin{array}{c}\text { Water + 0.1\% v/v } \\
\text { formic acid } \\
{[\%]}\end{array}$ & $\begin{array}{c}\text { Acetonitrile }+0.1 \% \\
\text { v/v formic acid } \\
{[\%]}\end{array}$ & & $\begin{array}{c}\text { Water }+2.5 \text { mmol } \\
\text { ammonium acetate }[\%]\end{array}$ & $\begin{array}{l}\text { Methanol }+2.5 \mathrm{mmol} \\
\text { ammonium acetate } \quad[\%]\end{array}$ \\
\hline & 0.0 & 65 & 35 & 0.0 & 80 & 20 \\
\hline & 0.5 & 65 & 35 & 1.0 & 80 & 20 \\
\hline & 6.0 & 20 & 80 & 6.0 & 50 & 50 \\
\hline & 7.0 & 0 & 100 & 8.0 & 50 & 50 \\
\hline & 7.5 & 0 & 100 & 9.0 & 0 & 100 \\
\hline & 8.1 & 65 & 35 & 10.0 & 0 & 100 \\
\hline & 10.0 & 65 & 35 & 10.5 & 80 & 20 \\
\hline & & & & 14.0 & 80 & 20 \\
\hline
\end{tabular}

The UHPLC system was coupled to a QTRAP 6500+ mass spectrometer from AB Sciex. In positive mode, an electrospray Turbo V Ionization Source with a voltage of $5500 \mathrm{~V}$, a desolvation temperature of $500{ }^{\circ} \mathrm{C}$, a curtain gas of 25 psig and a turbo gas of $50 \mathrm{psig}$, was used. In the negative mode, an atmospheric pressure chemical ionization (APCI) Turbo V Ionization Source was used to detect NG and 2,4-DNT. As NG was degraded at high temperature and 2,4-DNT was poorly ionized at low temperature, different parameters were used for these two molecules. A source temperature of $137.5^{\circ} \mathrm{C}$, a curtain gas of $30 \mathrm{psig}$ and an ion source gas of $36 \mathrm{psig}$ were used for the NG, while a source temperature of $425{ }^{\circ} \mathrm{C}$, a curtain gas of $27.5 \mathrm{psig}$ and an ion source gas of 40 psig were used for the 2,4-DNT. Quantification was performed using selected reaction monitoring (SRM) measurements. Analyst ${ }^{\circledR}$ and MultiQuant ${ }^{\circledR}$ 3.0.2 software packages allowed instrument control, data acquisition and treatment. The semi-quantitative determination of OGSR concentration was performed using a calibration curve (10 duplication levels) for each compound.

Eight compounds were selected in this study as they are commonly detected after the discharge of a firearm and they are reported to be the main components of the smokeless powder chosen for the study $(16,23,28,38)$ (Table 3). Diphenylamine was obtained from Fluka (Buchs, Switzerland). Akardite II, ethylcentralite, N-nitrosodiphenylamine and 4nitrodiphenylamine were purchased from Sigma-Aldrich (Buchs, Switzerland). 2-nitrodiphenylamine was obtained from Alfa Aesar (Karlsruhe, Germany). For these last compounds, stock solutions were prepared at a concentration of $1 \mathrm{mg} / \mathrm{mL}$ in methanol and stored at $4{ }^{\circ} \mathrm{C}$. Nitroglycerin and 2,4-dinitrotoluene were from AccuStandard (Niederbipp, Switzerland). These compounds were bought as stock solutions. Nitroglycerin was obtained at a concentration of $0.1 \mathrm{mg} / \mathrm{mL} \mathrm{in} \mathrm{ethanol}$ $(1: 10(\mathrm{v} / \mathrm{v}))$ while the 2,4-dinitrotoluene was received at a concentration of $1 \mathrm{mg} / \mathrm{mL}$ in methanol:acetonitrile $(1: 1(\mathrm{v} / \mathrm{v}))$. 
Table 3. Target OGSR compounds and MS/MS parameters.

\begin{tabular}{|c|c|c|c|c|c|c|c|}
\hline Compound & $\begin{array}{c}\text { Parent } \\
\text { ion }[\mathrm{m} / \mathrm{z}]\end{array}$ & $\begin{array}{c}\text { Declustering } \\
\text { potential } \\
{[\mathrm{V}]}\end{array}$ & $\begin{array}{c}\text { LOD } \\
{[\mathrm{ng} / \mathrm{mL}]}\end{array}$ & $\begin{array}{c}\text { Product } \\
\text { ion } \\
{[\mathrm{m} / \mathrm{z}]}\end{array}$ & $\begin{array}{c}\text { Collision } \\
\text { energy } \\
{[\mathrm{V}]}\end{array}$ & $\begin{array}{c}\text { Collision Cell } \\
\text { Exit Potential } \\
{[\mathrm{V}]}\end{array}$ & $\begin{array}{l}\text { Ionization } \\
\text { mode }\end{array}$ \\
\hline \multirow{2}{*}{$\begin{array}{l}\text { Akardite II } \\
\text { (AK-II) }\end{array}$} & \multirow{2}{*}{$\begin{array}{c}227.0 \\
{[\mathrm{M}+\mathrm{H}]^{+}}\end{array}$} & \multirow{2}{*}{61} & \multirow{2}{*}{0.005} & 170.0 & 33 & 20 & \multirow{2}{*}{ ESI+ } \\
\hline & & & & 91.0 & 23 & 10 & \\
\hline \multirow{2}{*}{$\begin{array}{l}\text { Ethylcentralite } \\
\text { (EC) }\end{array}$} & \multirow{2}{*}{$\begin{array}{c}269.1 \\
{[\mathrm{M}+\mathrm{H}]^{+}}\end{array}$} & \multirow{2}{*}{40} & \multirow{2}{*}{0.005} & 148.0 & 29 & 16 & \multirow{2}{*}{ ESI+ } \\
\hline & & & & 120.0 & 19 & 10 & \\
\hline \multirow{2}{*}{$\begin{array}{l}N \text {-nitrosodiphenylamine } \\
(N \text {-nDPA })\end{array}$} & \multirow{2}{*}{$\begin{array}{c}199.0 \\
{[\mathrm{M}+\mathrm{H}]^{+}}\end{array}$} & \multirow{2}{*}{21} & \multirow{2}{*}{0.02} & 66.0 & 29 & 8 & \multirow{2}{*}{ ESI+ } \\
\hline & & & & 169.0 & 15 & 20 & \\
\hline \multirow{2}{*}{$\begin{array}{c}\text { Diphenylamine } \\
\text { (DPA) }\end{array}$} & \multirow{2}{*}{$\begin{array}{c}170.1 \\
{[\mathrm{M}+\mathrm{H}]^{+}}\end{array}$} & \multirow{2}{*}{51} & \multirow{2}{*}{0.2} & 93.0 & 25 & 10 & \multirow{2}{*}{ ESI+ } \\
\hline & & & & 92.1 & 31 & 10 & \\
\hline \multirow{2}{*}{$\begin{array}{l}\text { 2-nitrodiphenylamine } \\
\text { (2-nDPA) }\end{array}$} & \multirow{2}{*}{$\begin{array}{c}215.0 \\
{[\mathrm{M}+\mathrm{H}]^{+}}\end{array}$} & \multirow{2}{*}{91} & \multirow{2}{*}{0.02} & 180.0 & 19 & 20 & \multirow{2}{*}{ ESI+ } \\
\hline & & & & 198.0 & 23 & 20 & \\
\hline \multirow{2}{*}{$\begin{array}{l}\text { 4-nitrodiphenylamine } \\
\text { (4-nDPA) }\end{array}$} & \multirow{2}{*}{$\begin{array}{c}215.0 \\
{[\mathrm{M}+\mathrm{H}]^{+}}\end{array}$} & \multirow{2}{*}{191} & \multirow{2}{*}{0.05} & 198.0 & 43 & 20 & \multirow{2}{*}{ ESI+ } \\
\hline & & & & 167.0 & 21 & 18 & \\
\hline $\begin{array}{l}\text { Nitroglycerin } \\
\quad(\mathrm{NG})\end{array}$ & $\begin{array}{l}227 \\
{[\mathrm{M}]^{-}}\end{array}$ & -5 & 10 & $\begin{array}{l}107.8 \\
62.0\end{array}$ & -7 & -10 & APCI- \\
\hline \multirow{2}{*}{$\begin{array}{l}\text { 2,4-Dinitrotoluene } \\
\text { (2,4-DNT) }\end{array}$} & \multirow{2}{*}{$\begin{array}{c}181 \\
{[\mathrm{M}-\mathrm{H}]^{-}}\end{array}$} & -78 & 008 & 135.0 & & -11 & APCI- \\
\hline & & -5 & & 46.0 & 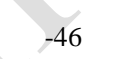 & -21 & APC1- \\
\hline
\end{tabular}

* LOD, Limit Of Detection; ESI, ElectroSpray Ionization; APCI, Atmospheric Pressure Chemical Ionization.

\subsubsection{SEM-EDX analysis}

Inorganic GSR analysis was performed using a SEM-EDX, the EVO MA 15 from Zeiss (Germany) equipped with an 80 $\mathrm{mm} 2 \mathrm{X}$-Max detector from Oxford Instruments (Germany). The research and detection of inorganic particles on the stubs was automated using the INCA Energy software also from Oxford Instruments (Germany). The search was performed with an accelerating voltage of $20 \mathrm{kV}$ for the detection of heavy elements and a working distance of $8.5 \mathrm{~mm}$. The particles were classified according to the ASTM guidelines, which is standard practice for the analysis of IGSR by SEM-EDX (3) (Table 4). The entire surface of the adhesive was analyzed for each protocol. After the analysis, no manual confirmation of the elemental composition and shape of particles classified as characteristic, consistent or commonly associated with GSR was performed. This step is important as part of a criminal investigation to confirm the classification but was considered to be less relevant (and very time consuming) in a research perspective. Thus, the presented results were obtained automatically and are indicative of the actual number of particles. For the Fifty-Fifty sampling, the particles detected in the "OGSR half" of the adhesive were manually removed (on the Excel sheet generated by the INCA Energy Software).

Table 4. Classification of the inorganic particles (3).

\begin{tabular}{ccc}
\hline Classification & Definition & Elemental Compositions \\
\hline Characteristic particles & Compositions rarely found from another source & PbSbBa, PbBaCaSiSn, GdTiZn, GaCuSn \\
Consistent particles & $\begin{array}{c}\text { Compositions found from a number of relatively } \\
\text { common non firearm sources }\end{array}$ & $\mathrm{PbBaCaSi}, \mathrm{BaCaSi}, \mathrm{SbBa}, \mathrm{PbSb}, \mathrm{BaAl}, \mathrm{PbBa}, \mathrm{TiZn}, \mathrm{Sr}$ \\
Commonly associated particles & $\begin{array}{c}\text { Compositions commonly found in environmental } \\
\text { from numerous sources }\end{array}$ & $\begin{array}{c}\text { Particles with one of the following composition: Pb, Sb or } \\
\text { Ba (sulfur can be present) }\end{array}$ \\
\hline
\end{tabular}

\section{Results and discussion}

The results obtained for the three combined protocols were compared. First, the number of characteristic particles were compared as they are considered relevant and rarely found from other sources (Table 4). Consistent and commonly associated particles were also considered. In a second step, the measured concentrations of OGSR target molecules were compared. Boxplots were used to illustrate the distribution of the results obtained for 10 replicas per protocol (39). 


\subsection{IGSR}

First, the particles having a characteristic composition were counted for each protocol (Figure 4). While a majority were composed uniquely of the three elements $\mathrm{Sb}, \mathrm{Ba}$ and $\mathrm{Pb}$, up to two characteristic particles per specimen were detected with more complex compositions [ $\mathrm{Sn}, \mathrm{Sb}, \mathrm{Ba}$ and $\mathrm{Pb}$ ] or [ $\mathrm{Pb}, \mathrm{Ba}, \mathrm{Ca}, \mathrm{Si}$ and $\mathrm{Sn}$ ]. These particles were included in the total characteristic particle count.

Figure 4. Boxplots representing the total number of characteristic particles detected from the sampling of the dominant hand of a shooter immediately after three consecutive discharges $(n=10 /$ protocol $)$.

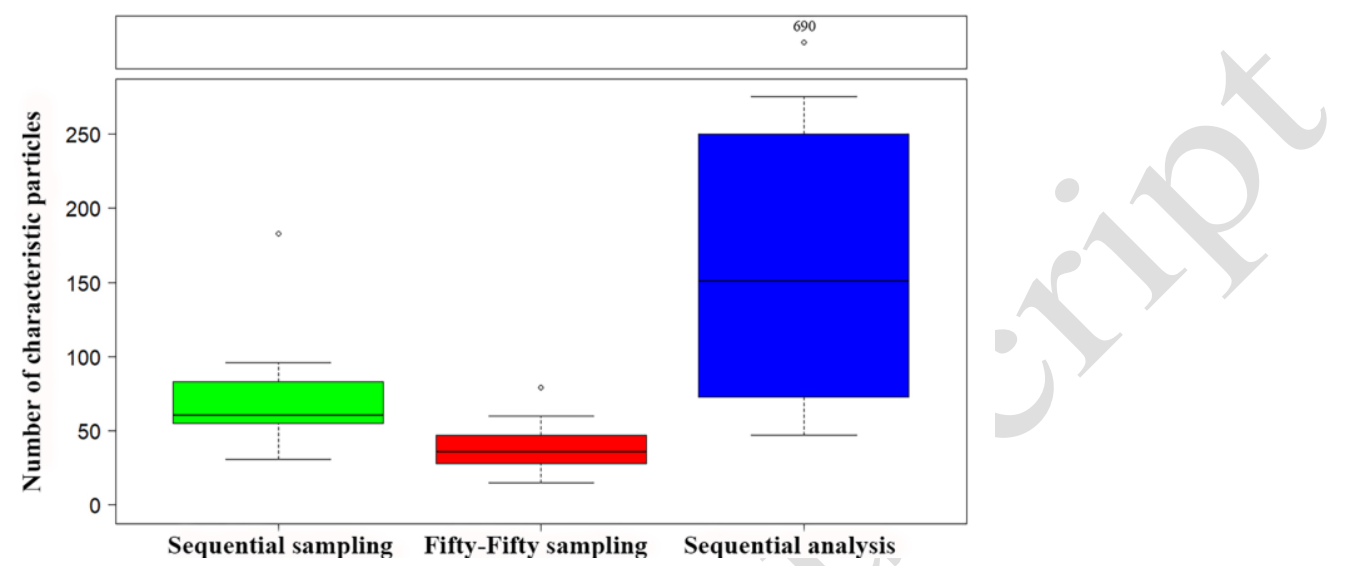

The highest number of characteristic particles (with a median of 151 particles in Figure 4) was obtained with the sequential analysis protocol. This method also showed the highest variance with a relative standard deviation (RSD) of $92 \%$ compared to $56 \%$ and $51 \%$ respectively for the sequential sampling and fifty-fifty sampling protocols (Table 5). One possible explanation can be given for these varying results. The sequential analysis protocol is the only one in which a carbon layer was applied. While in practice it is usually done to limit the charging effect caused by the presence of dust, skin flakes or fibers on the adhesive (37), it was applied here to prevent or limit the evaporation of the OGSR compound in the vacuum used for SEM-EDX analyses, in order to maximize the amount subsequently detected using UHPLC-MS/MS.

The sequential and fifty-fifty sampling protocols and were less efficient for the analysis of characteristic particles. Sequential sampling yielded a median of 60 characteristic particles, while the fifty-fifty sampling protocol yielded a median of 36 characteristic particles. Despite this lower result, the sequential sampling protocol remains a very interesting option for IGSR detection. The main difference with the two other protocols was the number and localization of the dabbings on the dominant hand: 15 dabbing on the thumb and forefinger area of the hand compared to 50 to 100 dabbings on the whole hand (thumb, forefinger, back and palm). The slightly lower number of detected characteristic particles might thus be explained by incomplete collection. Finally, the fifty-fifty sampling protocol yielded the lowest number of characteristic particles. This can be explained by the fact that only one half of the collected specimens was analysed for IGSR, the other half being extracted for OGSR analysis. The division of the adhesive in two equal parts means that theoretically half of the specimen is lost for each type of GSR. Moreover, the distribution of particles on the halves might be inhomogeneous and the analysis might lead to a false negative result if no IGSR or OGSR was found on one half.

The numbers of consistent particles were also compared between the three protocols. The five most frequently encountered elemental compositions are represented in Figure 5: $\mathrm{SbSnBa}, \mathrm{SbBa}, \mathrm{SbPb}, \mathrm{BaPb}$ and $\mathrm{SbSnPb}$. Again, sequential sampling and analysis yielded the highest values (with medians of 342 and 419 for SbBa respectively). The fifty-fifty sampling again yielded the lowest amount of consistent particles with a median of 124 for SbBa. For all three protocols, SbBa particles were detected in higher amounts, while $\mathrm{SbSnPb}$ was detected in the lowest amounts. Variations for these consistent particles were in the same order of magnitude for the three protocols (Table 5). 
Figure 5. Boxplots representing the total number of consistent particles ( $\mathrm{SbSnBa}, \mathrm{SbBa}, \mathrm{SbPb}, \mathrm{BaPb}, \mathrm{SbSnPb}$ ) recovered from the dominant hand of a shooter following three consecutive discharges $(n=10 /$ protocol $)$.
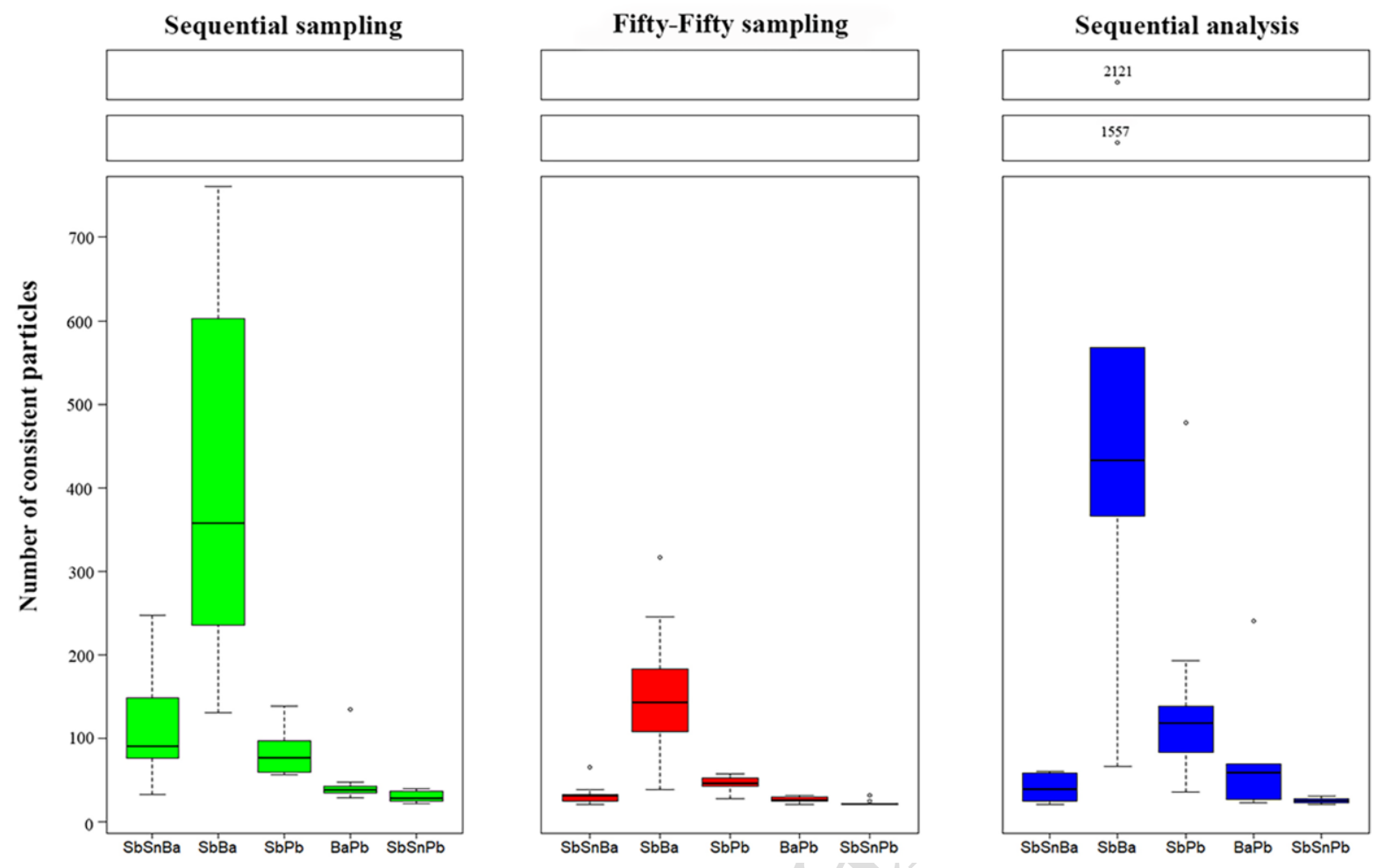

Table 5. Results representing the number and variance of IGSR recovered from the dominant hand of a shooter following three consecutive discharges.

\begin{tabular}{|c|c|c|c|c|c|c|c|}
\hline \multirow{3}{*}{ Class of particles } & \multirow{3}{*}{ Composition } & \multicolumn{6}{|c|}{ Protocol } \\
\hline & & \multicolumn{2}{|c|}{ Sequential sampling } & \multicolumn{2}{|c|}{ Fifty-fifty sampling } & \multicolumn{2}{|c|}{ Sequential analysis } \\
\hline & & $\begin{array}{c}\text { Median } \\
\text { [\# particles] }\end{array}$ & $\begin{array}{l}R S D \\
{[\%]}\end{array}$ & $\begin{array}{c}\text { Median } \\
\text { [\# particles] }\end{array}$ & $\begin{array}{l}R S D \\
{[\%]}\end{array}$ & $\begin{array}{c}\text { Median } \\
\text { [\# particles] }\end{array}$ & $\begin{array}{l}R S D \\
{[\%]} \\
\end{array}$ \\
\hline Characteristic & $\begin{array}{c}\text { SbBaPb, SnSbBaPb, } \\
\text { PbBaCaSiSn }\end{array}$ & 60 & 56 & 36 & 51 & 151 & 92 \\
\hline \multirow{5}{*}{ Consistent } & SbSnBa & 70 & 78 & 10 & 106 & 18 & 79 \\
\hline & $\mathrm{SbBa}$ & 342 & 54 & 124 & 59 & 419 & 98 \\
\hline & $\mathrm{SbPb}$ & 56 & 46 & 25 & 37 & 98 & 104 \\
\hline & BaPb & 17 & 116 & 5 & 63 & 38 & 130 \\
\hline & SbSnPb & 7 & 69 & 0 & 206 & 4 & 79 \\
\hline \multirow{4}{*}{$\begin{array}{c}\text { Commonly } \\
\text { associated with } \\
\text { GSR }\end{array}$} & SbSn & 25 & 94 & 3 & 92 & 10 & 82 \\
\hline & $\mathbf{S b}$ & 160 & 75 & 13 & 121 & 80 & 144 \\
\hline & $\mathbf{P b}$ & 39 & 58 & 14 & 61 & 74 & 120 \\
\hline & $\mathbf{B a}$ & 236 & 66 & 25 & 130 & 244 & 95 \\
\hline
\end{tabular}

Particles classified as commonly associated with GSR were also detected in the specimens (Figure 6 and Table 5). A high number of particles having the elemental composition SbBa were detected with the sequential sampling (respective median values of 160 and 236 particles) and the sequential analysis protocol (respective median values of 80 and 244 particles). The fifty-fifty sampling protocol recovered fewer particles with these elemental compositions (median values of 13 and 25 particles for SbBa particles). Variations were also in the same order of magnitude for the three protocols (Table 5). 
Figure 6. Boxplots representing the total number of commonly associated with GSR particles ( $\mathrm{SbSn}, \mathrm{Sb}, \mathrm{Pb}, \mathrm{Ba}$ ) recovered from the dominant hand of a shooter following three consecutive discharges $(\mathrm{n}=10 /$ protocol $)$.
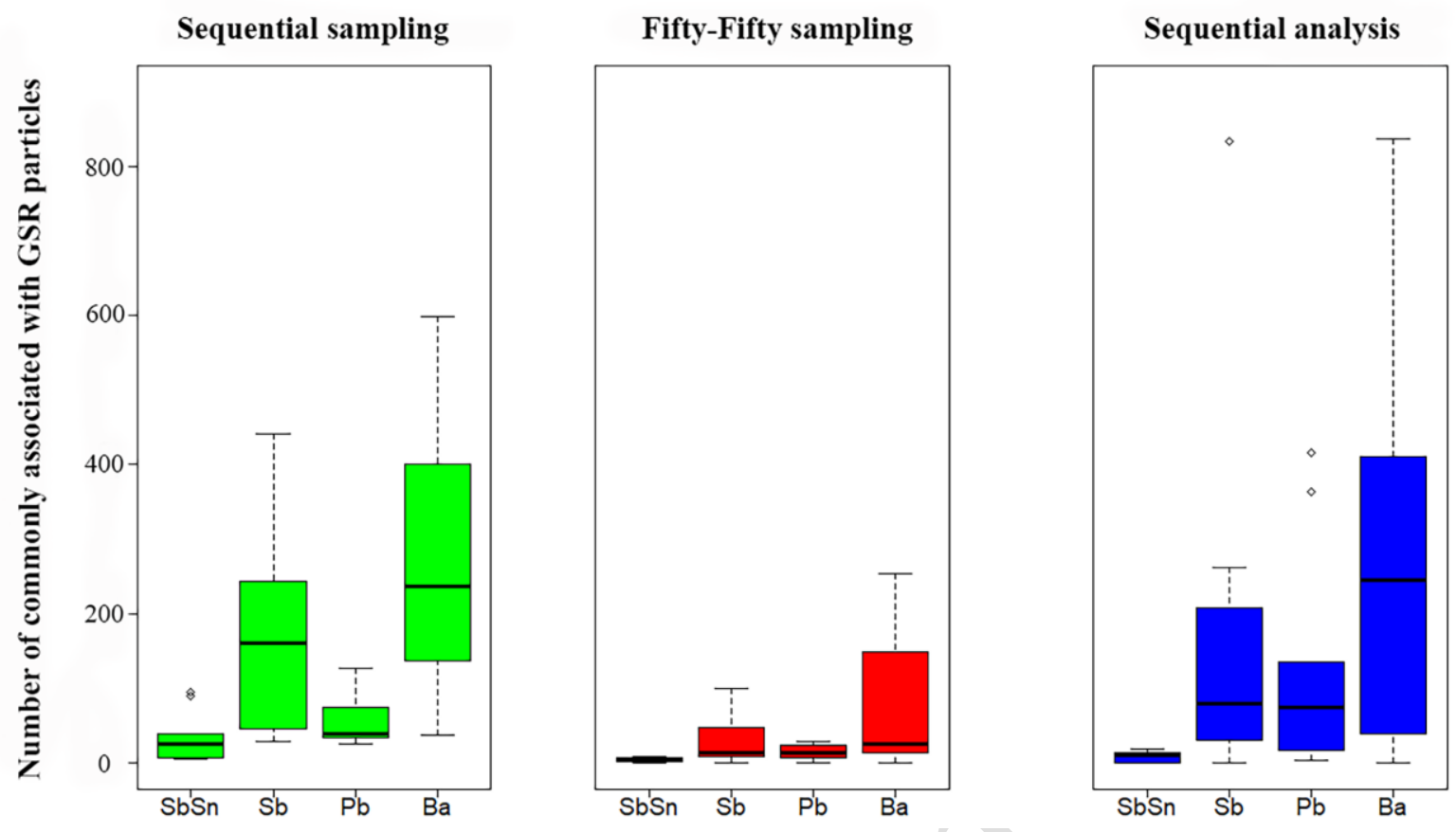

The sequential analysis protocol proved to be the most adequate for the analysis of IGSR considering the number of characteristic, consistent and commonly associated with GSR particles detected. This approach corresponds closely to actual practice in forensic laboratories (number of dabbings, use of a carbon layer and sampling of the whole dominant hand). It is important to note that IGSR analysis needs to be performed first due to the destructivity of OGSR analysis by UHPLCMS/MS. The sequential sampling protocol seems to generate lower values of characteristic and consistent particles. It would be a viable alternative if the sampling were performed immediately after shooting. Both of these protocols prioritise IGSR analysis as is done in practice (one for the sampling and the other for the analysis). However, recovery of OGSR might be the key parameter to determine which protocol is best suited in practice. The fifty-fifty sampling protocol will always yield less GSR of both types as one random half is analysed for IGSR and the other for OGSR. While still yielding adequate numbers of particles immediately after shooting, this approach might be inadequate for the collection of IGSR several hours after the discharge. If the few IGSR particles left on a shooter (skin, clothes, hair) are collected on the "wrong" half of the specimen, they will remain undetected. The number and localization of the dabbings on one hand for the sequential sampling protocol - 15 dabbings on the thumb and forefinger area - might also be less adequate for the collection of IGSR several hours after discharge.

\subsection{OGSR}

Eight targeted OGSR compounds were detected in the specimens and results for the three protocols were compared. The highest concentrations were obtained for NG (Figure 7). NG is the main explosive compound present in double and triple base smokeless powders (together with nitrocellulose, or nitrocellulose and nitroguanidine, respectively) (1, 17, 20, 38). Interestingly, the sequential analysis protocol yielded the highest concentration of $\mathrm{NG}$ with a median value of $2.10 \mu \mathrm{g} / \mathrm{mL}$ (Table 6). Contrary to IGSR results, the lowest variance was observed with this method (RSD of $75 \%$ compared to RSD of $99 \%$ and $184 \%$ for the fifty-fifty sampling and the sequential sampling). Lower concentrations were recovered with the sequential sampling and fifty-fifty sampling protocols (median values of respectively 0.17 and $0.33 \mu \mathrm{g} / \mathrm{mL}$ ). These lower concentrations can be explained by the collection of OGSR respectively on the first stub and on the other half of the adhesive that were analysed for IGSR, thus representing a significant loss of OGSR. 
Figure 7. Boxplots representing the amount of NG recovered from the dominant hand of a shooter immediately after three consecutive discharges $(\mathrm{n}=10 /$ protocol $)$.

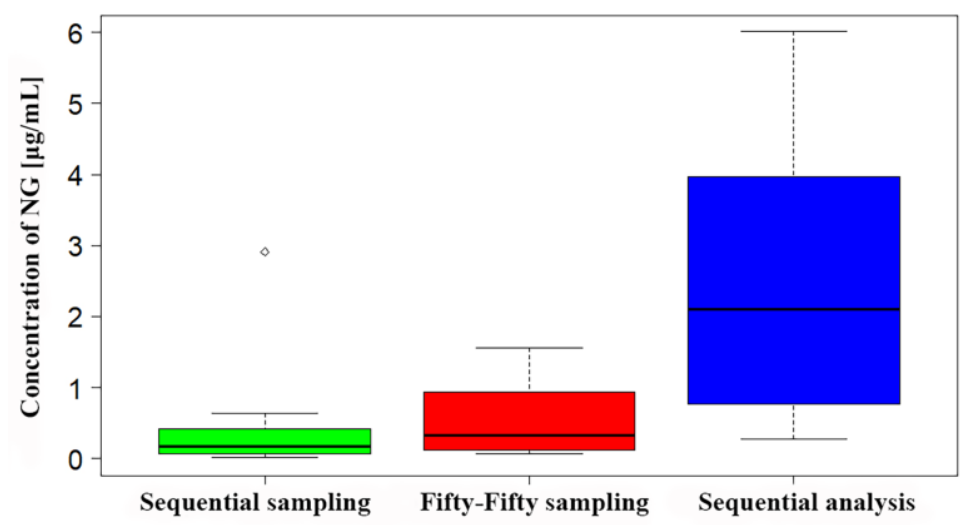

Table 6. Results representing the amount and variance of OGSR (NG, DPA, AK-II, 4-nDPA, $N$-nDPA, 2-nDPA, EC, 2.4-DNT) recovered from the hand of a shooter following three consecutive discharges $(\mathrm{n}=10$ / protocol $)$.

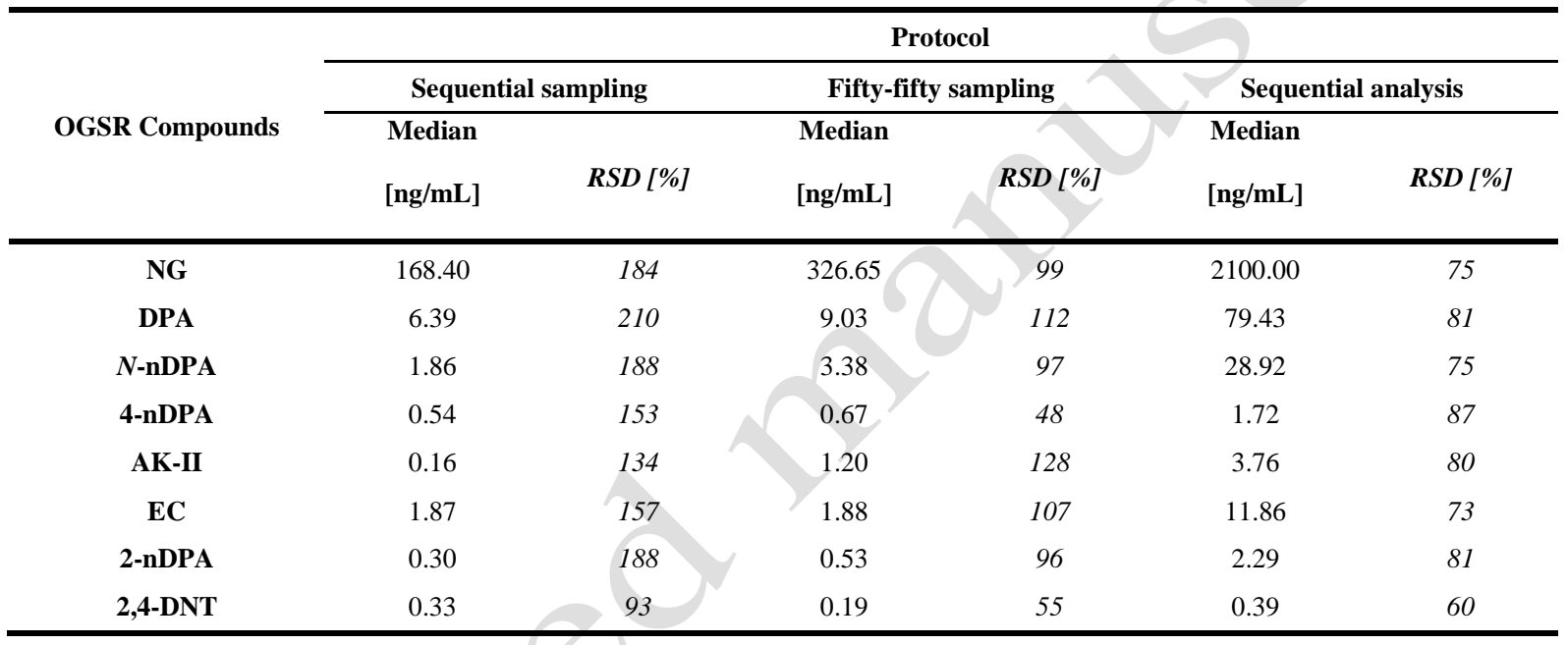

DPA was also detected in relatively high concentrations in the specimens (Figure 8). This compound is generally added to the powder as a stabilizing agent and was reported as one of the most frequently detected OGSR after NG (19, 21, 28). Again, higher concentrations of DPA were obtained using sequential analysis (median value of $79.4 \mathrm{ng} / \mathrm{mL}$ ), while lower concentrations were recovered with the sequential sampling and the fifty-fifty sampling protocols (median values of respectively 6.4 and $9.0 \mathrm{ng} / \mathrm{mL}$ ). As for the $\mathrm{NG}$, the lowest variance was obtained with the sequential analysis (RSD of 81 $\%$ compared to RSD of $112 \%$ and $210 \%$ for the fifty-fifty sampling and the sequential sampling).

Figure 8. Boxplots representing the amount of DPA recovered from the dominant hand of a shooter immediately after three consecutive discharges $(\mathrm{n}=10 /$ protocol $)$.

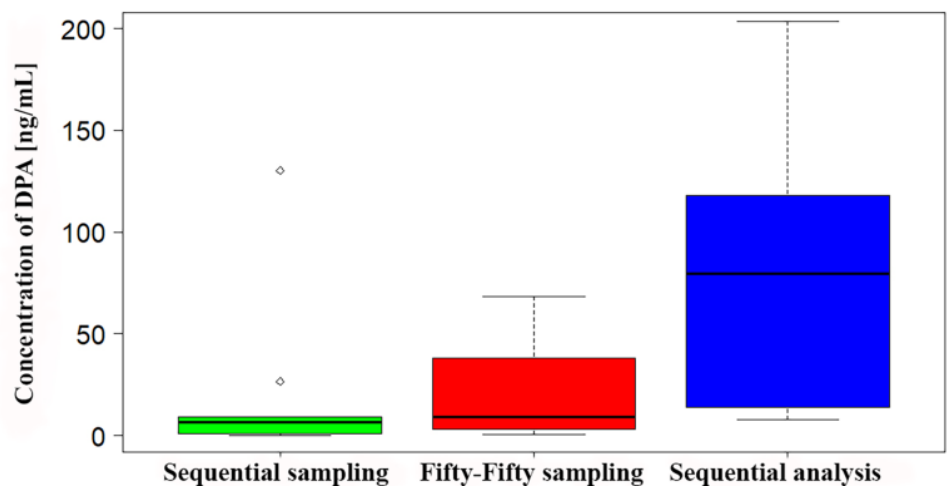


Concentrations below $80 \mathrm{ng} / \mathrm{mL}$ were recovered for the N-nDPA, 4-nDPA, AK-II, EC, 2-nDPA and 2,4-DNT. The highest concentrations were always obtained using the sequential analysis protocol, while low concentrations (sometimes nothing were detected in specimens) were obtained using the sequential and fifty-fifty sampling protocols (Table 6).

These results showed that the sequential analysis approach using one stub to collect both types of residue was the best method for OGSR analysis, as well as for IGSR, when sampling was performed immediately after discharge. As previously mentioned, the drawback of this method is the potential loss of OGSR during the SEM-EDX analysis, as each stub is kept under high vacuum for between 20 to 30 hours. It appears that the loss of OGSR generated by the SEM-EDX (if any) was lower than the amount of OGSR lost during the sampling step of the two other protocols (fifty-fifty and sequential sampling). The lower concentrations obtained using the fifty-fifty sampling protocol can be explained by the fact that only one half of the stub was extracted for OGSR. It means that theoretically only $50 \%$ of the OGSR were recovered with this sampling approach. However, the obtained median values were generally more than $50 \%$ lower than those obtained with the sequential analysis protocol (e.g. under $20 \%$ for NG, DPA, N-nDPA and EC). The lowest concentrations of OGSR were obtained using the sequential sampling protocol. Several hypotheses might explain these lower values: 1) the Tesa ${ }^{\circledR}$ TACK was less efficient than the carbon stub for the collection of OGSR, 2) a large portion of OGSR was already collected with the first stub (used for IGSR analysis), 3) the OGSR molecules were lost during storage. It is possible that some target compounds were lost from the stub during storage at $4{ }^{\circ} \mathrm{C}$ over $2-7$ days, as reported by Taudte et al. (40). The fact that 2,4-DNT seemed the least affected by storage as a high median value was actually recovered for all protocols (median values of 0.19 , 0.33 and $0.39 \mathrm{ng} / \mathrm{mL}$ for the fifty-fifty, sequential sampling and sequential analysis protocols respectively) seems to indicate that evaporation might indeed be the main explanation for the loss of the other molecules. Energetic compounds (RDX, HMX, TNT, 2,4-DNT) are less volatile since they have lower vapor pressure values. They were also reported as more stable (than NG, DPA, N-nDPA, EC) under the same storage conditions (40). Thus, carbon coating might also protect these target molecules from evaporation before analysis. To corroborate these explanations, future tests regarding the suitability of adhesives, the sampling sequence, the carbon coating and storage conditions should be performed.

\section{Conclusions}

The purpose of this work was to evaluate the potential of three protocols for the combined collection and analysis of IGSR and OGSR. Results showed that collection of GSR immediately after discharge $(\mathrm{t} \approx 0)$, using one carbon stub followed by the sequential analysis using SEM-EDX and UHPLC-MS/MS, yielded the highest amounts of characteristic IGSR particles and OGSR target compounds. The carbon coating, moreover, seemed to protect against evaporation of OGSR molecules on the stub before extraction was carried out. The two other protocols evaluated were less efficient, probably because only one fraction of the sampling material was analyzed for IGSR, while the other part was extracted for OGSR recovery, thus yielding substantial loss of both types of residues. Regarding the fifty-fifty sampling, this lower efficiency can partially be explained by theoretical $50 \%$ loss caused by halving the stubs. However, the loss was well over $50 \%$ for several targeted GSR components. The fact that no carbon coating was applied to the stubs before IGSR analysis and OGSR extraction might also explain higher losses. Carbon coating appeared to have a positive effect on the recoveries of both types of GSR: it is known to decrease the influence of skin flakes, dust particles and fibers during the SEM-EDX analysis and additionally seemed to significantly decrease the loss of OGSR by trapping the molecules on the stub. Finally, the sequential sampling protocol minimized IGSR loss, but recovered concentrations of OGSR were particularly low. It might also be due to the efficiency of the collection material (the second stub used for OGSR collection was coated with another type of adhesive) or due to loss of the targeted molecules during storage. This protocol was additionally more time consuming as collection was carried out using two stubs, thus differing from current sampling procedures for IGSR. Further work is required to evaluate the factors influencing recovery efficiency, particularly when GSR collection is performed some time after the discharge, as is usual in practice.

A method based on sequential analysis of IGSR and OGSR can easily be integrated in forensic science laboratories as a routine collection and analysis procedure. The collection procedure, using stubs, is the same as currently applied for the collection of IGSR. Carbon coating is also advised for the current IGSR analysis using SEM-EDX. The actual added value would be the possibility to additionally analyze OGSR using UHPLC-MS/MS after a liquid extraction of the stub following the routine IGSR analysis. To implement a method for the combined collection and analysis of IGSR and OGSR, it is important to understand the benefits of this new approach. Since more compounds and elements are targeted, the probative value of GSR evidence would be strengthened. Additional information in the chemical profile might also provide additional knowledge about the type of ammunition used. However, the combined analysis also has a cost as two relatively expensive instrumentations have to be used. While SEM-EDX is readily available in GSR forensic laboratories, UHPLC-MS/MS is mainly used for explosive or drug analysis (and might thus be available in another sector of a forensic laboratory). Moreover, SEM-EDX analysis can lead to a loss of OGSR, while LC-MS is a destructive technique that would not enable subsequent analysis of the stubs for IGSR. Forensic laboratories will need to choose which type of GSR to focus on. The sequential analysis protocol enables routine analysis of IGSR to be conducted with minimal alteration, and, depending on the obtained results, OGSR analysis could then be performed if deemed useful to a particular case (for example if little IGSR is found or when heavy-metal free ammunition was known to be used). Future studies are needed to evaluate further the potential and probative value of OGSR in practical casework. 


\section{Acknowledgments}

They also would like to thank the Electron Microscopy Facility (EMF) of the Faculty of Biology and Medicine at the University of Lausanne (UNIL) for the carbon coating experiments, the Kantonspolizei Aargau for the SEM-EDX analyses, Olivier Robyr from Microscan service SA, and Dr. Arie Zeichner for their advices and expertise concerning IGSR analyses.

\section{References}

1. Meng H, Caddy B. Gunshot residue analysis — a review. Journal of Forensic Science. 1997; 42(4): 553-70.

2. Dalby O, Butler D, Birkett J. Analysis of gunshot residue and associated materials - A review. J Forensic Sci. 2010; 55(4): 924-43.

3. ASTM E1588-17. Standard Practice for Gunshot Residue Analysis by Scanning Electron Microscopy/Energy Dispersive X-Ray Spectrometry. ASTM International. 2017.

4. Scientific Working Group-Gunshot Residue (SWGGSR). Guide for Primer Gunshot Residue Analysis by Scanning Electron Microscopy/Energy Dispersive X-Ray Spectrometry. 2011.

5. Niewoehner L, Wenz HW, Andrasko J, Beijer R, Gunaratnam L. ENFSI Proficiency Test Program on Identification of GSR by SEM/EDX. J Forensic Sci. 2003; 48(4): 786-93.

6. Biedermann A, Bozza S, Taroni F. Probabilistic evidential assessment of gunshot residue particle evidence (Part I): Likelihood ratio calculation and case pre-assessment using Bayesian networks. Forensic Sci Int. 2009; 191(1-3): 24-35.

7. Biedermann A, Bozza S, Taroni F. Probabilistic evidential assessment of gunshot residue particle evidence (Part II): Bayesian parameter estimation for experimental count data. Forensic Sci Int. 2011; 206(1-3): 103-10.

8. Cardinetti B, Ciampini C, Abate S, Marchetti C, Ferrari F, Di Tullio D, et al. A Proposal for Statistical Evaluation of the Detection of Gunshot Residues on a Suspect. The Journal of Scanning Miscroscopies. 2006; 28(3): 142-7.

9. Martiny A, Campos A, Sader M, Pinto M. SEM/EDS analysis and characterization of gunshot residues from Brazilian lead-free ammunition. Forensic Sci Int. 2008; 177(1): e9-e17.

10. Kanstrup N, Thomas VG, Krone O, Gremse C. The transition to non-lead rifle ammunition in Denmark: National obligations and policy considerations. Ambio. 2016; 45(5): 621-8.

11. Kelly TR, Bloom PH, Torres SG, Hernandez YZ, Poppenga RH, Boyce WM, et al. Impact of the California lead ammunition ban on reducing lead exposure in golden eagles and turkey vultures. PLoS One. 2011; 6(4): e17656.

12. Gunaratnam L, Himberg K. The Identification of Gunshot Residue Particles from Lead-Free Sintox Ammunition. J Forensic Sci. 1994; 39(2): 532-6.

13. Oommen Z, Pierce SM. Lead-free primer residues: a qualitative characterization of Winchester WinClean, Remington/UMC LeadLess, Federal BallistiClean, and Speer Lawman CleanFire handgun ammunition. J Forensic Sci. 2006; 51(3): 509-19.

14. Donghi M, Orsenigo S, Niewoehner L, Barth M, Fiocchi C, Pomi A. A new ammunition for forensic needs: FIOCCHI-RIS. Forensic Chemistry. 2019; 13.

15. Niewoehner L, Eichner S, Merkel J, Buchholz N. New Ammunitions for the German Police Forces Technical Guideline: cartridge 9mm x 19, pollutant reduced. 2006.

16. Goudsmits E, Sharples GP, Birkett JW. Preliminary classification of characteristic organic gunshot residue compounds. Sci Justice. 2016; 56(6): 421-5.

17. Cascio O, Trettene M, Bortolotti F, Milana G, Tagliaro F. Analysis of organic components of smokeless gunpowders: high-performance liquid chromatogaphy vs. micellar electrokinetic capillary chromatography. Electrophoresis. 2004; 25(10-11): 1543-7.

18. Taudte RV, Beavis A, Blanes L, Cole N, Doble P, Roux C. Detection of gunshot residues using mass spectrometry. BioMed research international. 2014; 2014.

19. Benito S, Abrego Z, Sánchez A, Unceta N, Goicolea MA, Barrio RJ. Characterization of organic gunshot residues in lead-free ammunition using a new sample collection device for liquid chromatographyquadrupole time-of-flight mass spectrometry. Forensic Sci Int. 2015; 246: 79-85. 
20. Gassner AL, Weyermann C. LC-MS method development and comparison of sampling materials for the analysis of organic gunshot residues. Forensic Sci Int. 2016; 264: 47-55.

21. Taudte RV, Roux C, Bishop D, Blanes L, Doble P, Beavis A. Development of a UHPLC method for the detection of organic gunshot residues using artificial neural networks. Analytical Methods. 2015; 7(18): 7447-54.

22. Laza D, Nys B, Kinder JD, Kirsch-De Mesmaeker A, Moucheron C. Development of a quantitative LCMSMS method for the analysis of common propellant powder stabilizers in gunshot residue. J Forensic Sci. 2007; 52(4): 842-50.

23. Moran JW, Bell S. Skin Permeation of Organic Gunshot Residue: Implications for Sampling and Analysis. Anal Chem. 2014; 86(12): 6071-9.

24. Bell S, Seitzinger L. From binary presumptive assays to probabilistic assessments: Differentiation of shooters from non-shooters using IMS, OGSR, neural networks, and likelihood ratios. Forensic Sci Int. 2016; 263: 176-85.

25. Abrego Z, Grijalba N, Unceta N, Maguregui M, Sanchez A, Fernandez-Isla A, et al. A novel method for the identification of inorganic and organic gunshot residue particles of lead-free ammunitions from the hands of shooters using scanning laser ablation-ICPMS and Raman micro-spectroscopy. Analyst. 2014; 139(23): 6232-41.

26. Gandy L, Najjar K, Terry M, Bridge C. A novel protocol for the combined detection of organic, inorganic gunshot residue. Forensic Chemistry. 2018; 8: 1-10.

27. Tarifa A, Almirall JR. Fast detection and characterization of organic and inorganic gunshot residues on the hands of suspects by CMV-GC-MS and LIBS. Sci Justice. 2015; 55(3): 168-75.

28. Taudte RV, Roux C, Blanes L, Horder M, Kirkbride KP, Beavis A. The development and comparison of collection techniques for inorganic and organic gunshot residues. Anal Bioanal Chem. 2016; 408(10): 2567-76.

29. Goudsmits E, Blakey LS, Chana K, Sharples GP, Birkett JW. The analysis of organic and inorganic gunshot residue from a single sample. Forensic Sci Int. 2019; 299: 168-73.

30. Morelato M, Beavis A, Ogle A, Doble P, Kirkbride P, Roux C. Screening of gunshot residues using desorption electrospray ionisation-mass spectrometry (DESI-MS). Forensic Sci Int. 2012; 217(1-3): 101-6.

31. Zeichner A, Eldar B. A novel method for extraction and analysis of gunpowder residues on double-side adhesive coated stubs. J Forensic Sci. 2004; 49(6).

32. Bell S, Feeney W. Single shot, single sample, single instrument detection of IGSR and OGSR using LC/MS/MS. Forensic Sci Int. 2019; 299: 215-22.

33. Morales EB, Vazquez ALR. Simultaneous determination of inorganic and organic gunshot residues by capillary electrophoresis. J Chromatogr A. 2004; 1061(2) :225-33.

34. Federal Criminal Police Office of Germany (BKA). Development of analytical methods for sensitive detection and identification of organic gunshot residues (OGSR) based on liquid chromatography-mass spectrometry (LC-MS) for routine casework. Project Number: HOME/2011/ISEC/AG/2504. 2017.

35. Hofstetter C, Maitre M, Beavis A, Roux CP, Weyermann C, Gassner AL. A study of transfer and prevalence of organic gunshot residues. Forensic Sci Int. 2017; 277: 241-51.

36. Zeichner A. Recent developments in methods of chemical analysis in investigations of firearm-related event. Anal Bioanal Chem. 2003; 376(8): 1178-91.

37. Schwoeble AJ, Exline DL. Current methods in forensic gunshot residue analysis. CRC Press. 2000.

38. Perret D, Marchese S, Gentili A, Curini R, Terracciano A, Bafile E, et al. LC-MS-MS determination of stabilizers and explosives residues in hand-swabs. Chromatographia. 2008; 68(7-8): 517-24.

39. Lem S, Onghena P, Verschaffel L, Van Dooren W. The heuristic interpretation of box plots. Learning and Instruction. 2013; 26: 22-35.

40. Taudte RV, Roux C, Beavis A. Stability of smokeless powder compounds on collection devices. Forensic Sci Int. 2017; 270: 55-60. 